\title{
A Novel Protocol for Detection of Senescence and Calcification Markers by Fluorescence Microscopy
}

\author{
Jaqueline Herrmann ${ }^{1,2,+}$, Milen Babic ${ }^{1,+}$, Markus Tölle ${ }^{1} \mathbb{1}$, Kai-Uwe Eckardt ${ }^{1}$, \\ Markus van der Giet ${ }^{1, *}$ and Mirjam Schuchardt ${ }^{1}$ (D) \\ 1 Department of Nephrology and Medical Intensive Care, Charité-Universitätsmedizin Berlin, Corporate \\ Member of Freie Universität Berlin, Humboldt-Universtität zu Berlin, and Berlin Institute of Health, \\ Hindenburgdamm 30, 12203 Berlin, Germany; Jaqueline.Herrmann@charite.de (J.H.); \\ Milen.Babic@charite.de (M.B.); Markus.Toelle@charite.de (M.T.); Kai-Uwe.Eckardt@charite.de (K.-U.E.); \\ Mirjam.Schuchardt@charite.de (M.S.) \\ 2 Department of Chemistry, Biochemistry and Pharmacy, Freie Universität Berlin, Königin-Luise Straße 2+4, \\ 14195 Berlin, Germany \\ * Correspondence: Markus.vanderGiet@charite.de \\ $\dagger$ These authors contribute equally to this work.
}

Received: 14 April 2020; Accepted: 11 May 2020; Published: 14 May 2020

\begin{abstract}
Vascular calcification and stiffening of the arterial wall is a systemic phenomenon that is associated with aging and it can be increased by several risk factors. The underlying mechanisms, especially the pathways of cellular senescence, are under current investigation. Easily manageable in vitro settings help to study the signaling pathways. The experimental setting presented here is based on an in vitro model using rat vascular smooth muscle cells and the detection of senescence and osteoblastic markers via immunofluorescence and RNAscope ${ }^{\mathrm{TM}}$. Co-staining of the senescence marker p21, the osteoblastic marker osteopontin, detection of senescence-associated heterochromatin foci, and senescence-associated $\beta$-galactosidase is possible within one test approach requiring fewer cells. The protocol is a fast and reliable evaluation method for multiplexing of calcifying and senescence markers with fluorescence microscopy detection. The experimental setting enables analysis on single cell basis and allows detection of intra-individual variances of cultured cells.
\end{abstract}

Keywords: calcification; senescence; smooth muscle cell; SA- $\beta$-galactosidase; senescence-associated heterochromatin foci

\section{Introduction}

Aging is associated with a variety of characteristic changes of the vessel wall [1]. There are several disorders, in which patients show signs of premature aging of vessels that appear much older than their biological age e.g., in chronic kidney disease [2-4]. A hallmark of vascular aging is a stiffening of the arterial wall with increasing pulse-wave velocity and the mineralization of vascular smooth muscle cells (VSMC) in the media layer of the vessel wall [1,5]. Treatment options are currently not available [5].

Resulting from clinical and basic research, there is strong evidence that vascular calcification and aging occur jointly $[4,6,7]$. Several underlying mechanisms are discussed for vessel mineralization, including, but not limited to, oxidative stress from various sources and resulting DNA damage, continuous inflammation, and activation of pro-osteogenic signaling pathways $[3,7,8]$. However, the underlying pathophysiological mechanisms need further clarification. Currently, several hypotheses exist regarding joint or consecutive appearance of calcification and senescence in a vicious cycle in smooth muscle cells e.g., induced by uremic toxins [4,9]. In addition, the senescence level can vary within and between cells and the tissue of the same individual [10]. It has to be illuminated whether, 
in one cell population, cells experience senescence and calcification jointly or consecutively, or whether aged vessels contain distinctly different cell populations of aged and calcified cells.

A better understanding of the underlying mechanisms inducing and linking calcification and senescence of VSMC in the vessel wall will be necessary for establishing promising treatment options.

Detecting cellular senescence is hampered by the heterogeneity of senescence markers. For the reliable identification of DNA damage and cell senescence, the detection of several known markers is necessary. Here, the increased messenger-ribonucleic acid (mRNA) and protein expression of the cell cycle protein and cyclin inhibitor p21 as well as the formation of senescence-associated heterochromatin foci (SAHF) and the accumulation of senescence-associated $\beta$-galactosidase (SA- $\beta$-Gal) are typically used [10-12]. Additionally, the cells often undergo morphological changes that are detectable by light microscopy. Cell mineralization is accompanied by a shift in expression of a wide array of different markers e.g., osteopontin (OPN) [3,13].

The study aims to develop a fast, robust, and easy to handle protocol by detection of SA- $\beta$-Gal, SAHF, p21, OPN, and control of cell morphology, on single cell basis in vitro in order to facilitate jointly and/or consecutively activation of senescence and calcification markers within the cells in a parallel experimental setting. Therefore, the described method combines ultrasensitive RNAscope ${ }^{\mathrm{TM}}$ in situ hybridization and immunohistochemistry in a multiplex approach requiring few cells. Other currently available experimental settings with their advantages and disadvantages are summarized in the supplementary Table S1. Briefly, the in situ hybridization technique enables the detection of various nucleotide sequences in cells and tissue by radioactive, fluorescence, or immunohistochemistry labeling and it permits a multiplex approach in the right experimental setting [14]. The protocol presented here utilizes RNAscope ${ }^{\mathrm{TM}}$, a technology that applies oligonucleotide probes and immunohistochemical or fluorescence-based detection [15]. The utilized RNAscope ${ }^{\mathrm{TM}}$ kit allows for the analysis of three targets of interest in one experimental setting by fluorescence-based detection.

For the establishment and optimization of the protocol steps, the known inductor of cell senescence, doxorubicin (Dox) [16], as well as a known inducer of cell mineralization, the uremic toxin uridine-adenosine tetraphosphate $\left(\mathrm{Up}_{4} \mathrm{~A}\right)$ [17], were used. The established protocol provides reliable data while requiring fewer primary cell numbers and, therefore, fewer animals per experiment by multiplexing several markers of interest.

\section{Results and Discussion}

Currently, several senescence markers for cells and tissue are known [10,11]. Often, the detection of more than one marker is used for reliable detection and the senescence levels can vary between cells and tissue, respectively, within the same animal [10].

Here, we provided a staining protocol for four markers of interest to detect senescence and osteoblastic differentiation in cells. Besides, the protocol can be expanded for the detection of other markers by using a laser-scanning microscope for image acquisition. The detection via fluorescence staining allows not only the visualization in individual cells, but also quantification for statistical analysis of the results.

\subsection{Detection of $S A-\beta-G a l$}

SA- $\beta$-Gal was selected as marker accumulating in cells during aging, according to previous studies $[6,10]$. The staining of the cells with SPiDER-SA-B-Gal upon stimulation with Dox, as a known inductor of cell senescence [16], results in the accumulation of SA- $\beta-G a l$ within the cytoplasm of the cell, as shown in Figure 1. In contrast, while $\mathrm{Up}_{4} \mathrm{~A}$ induces cell calcification [17], no accumulation of SA- $\beta-$ Gal could be detected upon stimulation of VSMC for $72 \mathrm{~h}$. For counterstaining of the nucleus, Hoechst stain was used. The quantification of the pixel sum intensity (Figure 2) confirmed the findings of the representative images that are shown in Figure 1. 


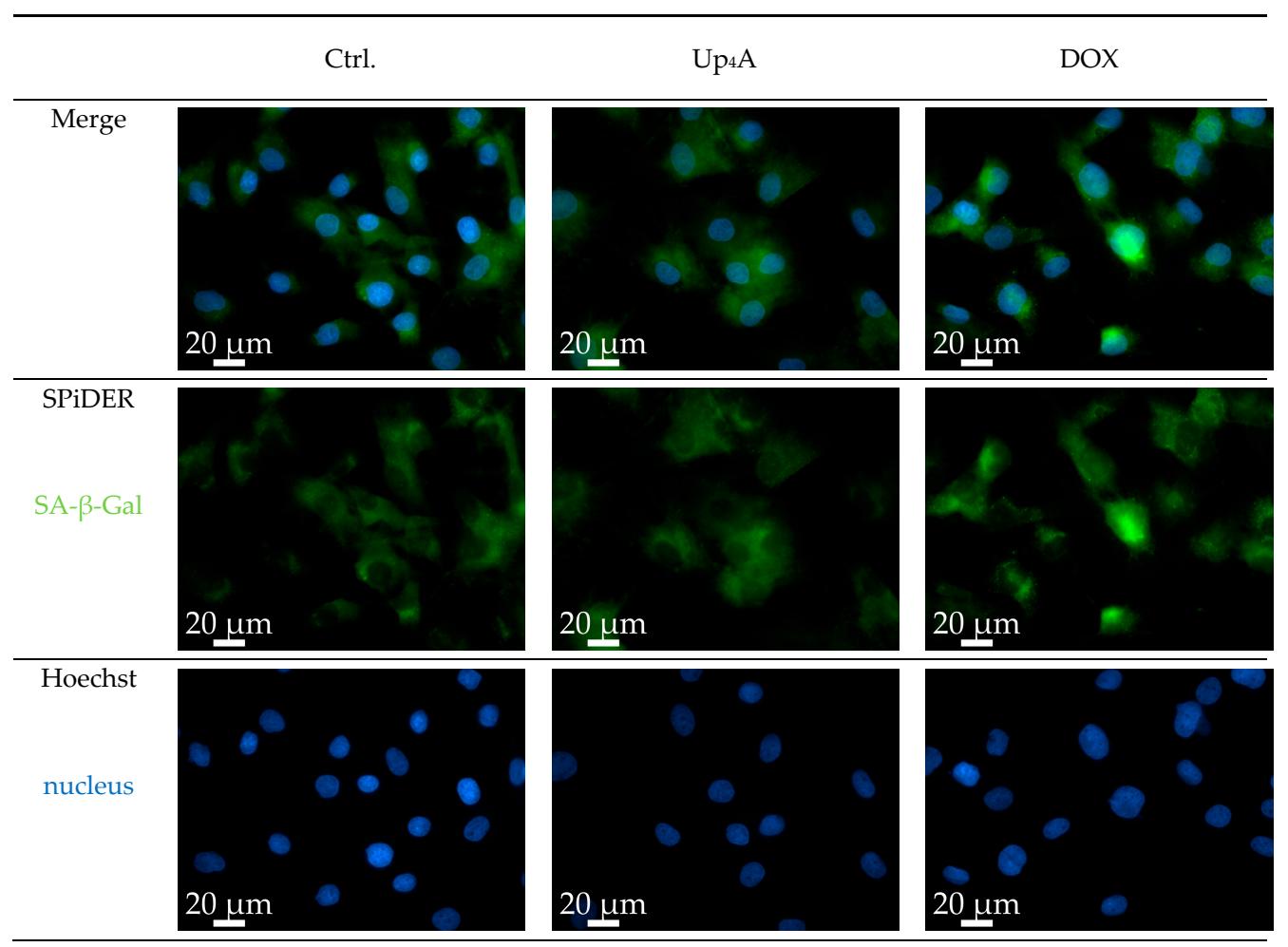

Figure 1. Detection of senescence-associated $\beta$-galactosidase (SA- $\beta$-Gal) in primary rat smooth muscle cells upon stimulation with doxorubicin (Dox, $500 \mathrm{nmol} / \mathrm{L}$ ) and uridine-adenosine tetraphosphate $\left(\mathrm{Up}_{4} \mathrm{~A}, 100 \mu \mathrm{mol} / \mathrm{L}\right)$ for $72 \mathrm{~h} .40 \times$ objective. Representative images out of three independent experiments. Ctrl.: control.

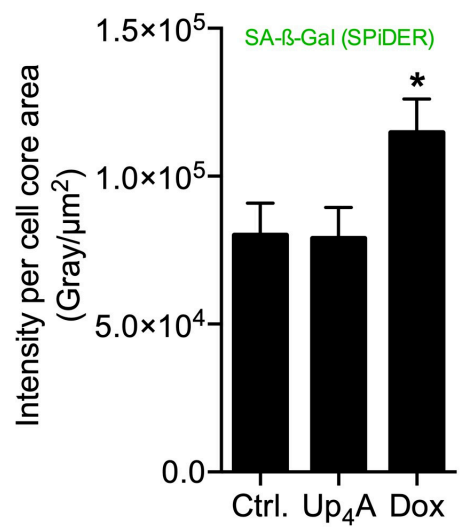

Figure 2. Quantification of senescence-associated $\beta$-galactosidase (SA- $\beta$-Gal) in primary rat smooth muscle cells upon stimulation with doxorubicin (Dox, $500 \mathrm{nmol} / \mathrm{L}$ ) and uridine-adenosine tetraphosphate $\left(\mathrm{Up}_{4} \mathrm{~A}, 100 \mu \mathrm{mol} / \mathrm{L}\right)$ for $72 \mathrm{~h}$. For analysis, intensity pixel sum per channel was normalized to cell core area. Bar graph represents mean \pm SEM of three independent experiments. Ctrl.: control.

The results suggest that accumulation of SA- $\beta-$ Gal in rat vascular smooth muscle cells (rVSMC) depends on the inductor and may be dependent on time for different inductors. This underlines the fact that the detection of more than one senescence marker often seems necessary [10].

\subsection{OPN and $p 21$ mRNA Detection and Detection of SAHF}

OPN was selected as a calcification marker, because its gene expression was increased by stimulation with different calcification inducers in previous experiments [17]. The gene expression of the cyclin inhibitor p21 is one typical marker used for the detection of cellular senescence $[6,10]$. 
Several experimental protocols currently exist for the detection of calcification or senescence markers in vascular cells (summarized in Table S1). However, the current goal was to use a single cell-based identification of a senescence and osteoblastic marker while using RNA in situ hybridization via RNAscope ${ }^{\mathrm{TM}}$ technology. The significant advantage is the multiplexing possibility of several target genes of interest in a cell and tissue sample in a robust way with high sensitivity [15]. Dox strongly induced SAHF and mRNA expression of p21, but only slightly induced OPN mRNA expression upon $48 \mathrm{~h}$ of stimulation, as shown in Figure 3. In contrast, upon $\mathrm{Up}_{4} \mathrm{~A}$ stimulation, OPN mRNA expression is induced profoundly, but no SAHF could be detected and p21 mRNA expression is not induced in VSMC.

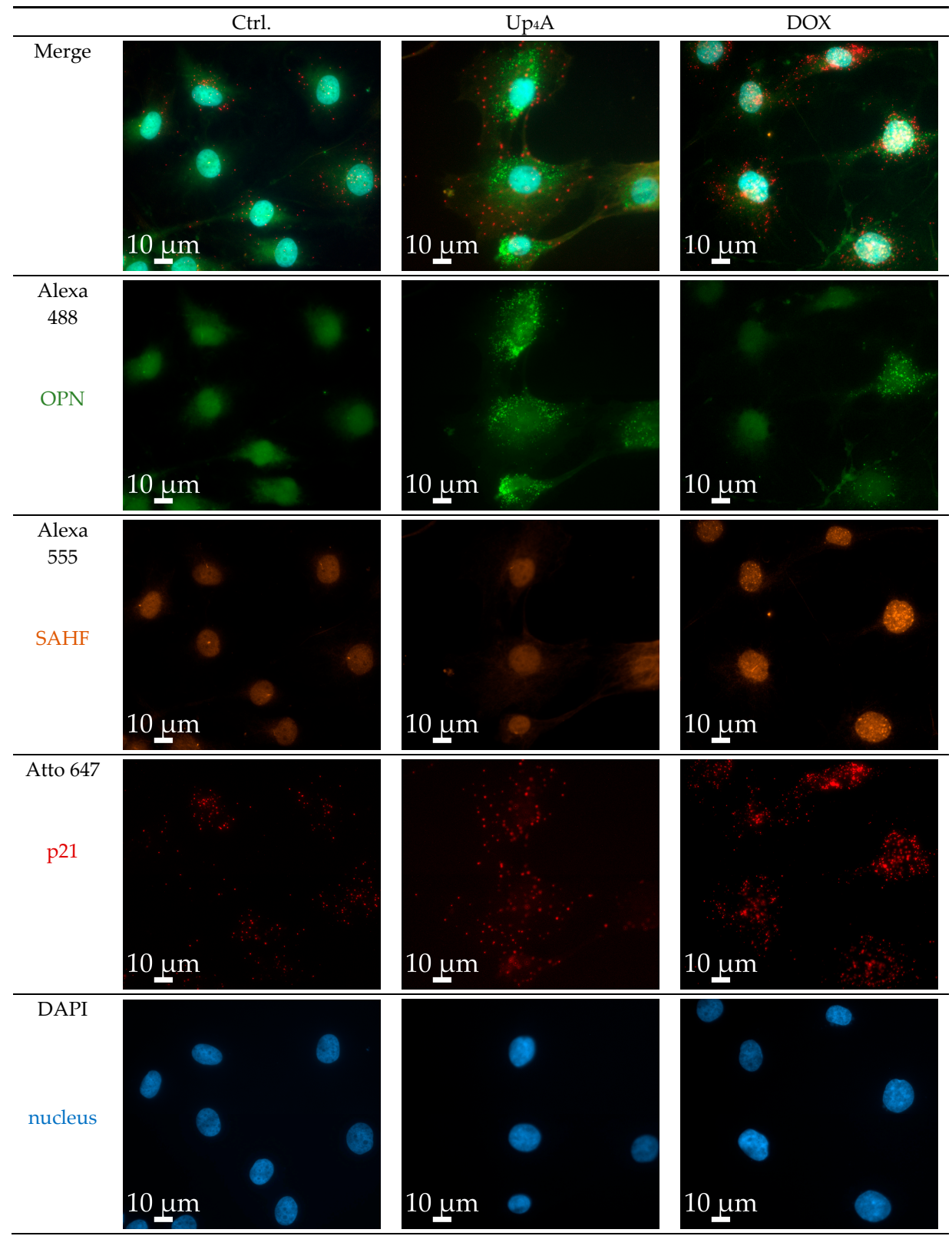

Figure 3. Detection of osteopontin (OPN), senescence-associated heterochromatin foci (SAHF), and p21 in primary rat smooth muscle cells upon stimulation with doxorubicin (Dox, $500 \mathrm{nmol} / \mathrm{L}$ ) and uridine-adenosine tetraphosphate $\left(\mathrm{Up}_{4} \mathrm{~A}, 100 \mu \mathrm{mol} / \mathrm{L}\right)$ for $48 \mathrm{~h}$. 40× objective. Representative images out of three independent experiments. Ctrl.: control. 
The quantification of the pixel sum intensity confirmed the findings for channel Atto 647 (Figure 4). The crosstalk between the channels Alexa 488 and Alexa 555 and the resulting background impedes the quantification of OPN mRNA expression and SAHF formation with a standardized, automated, and reproducible ZEN protocol in this experimental setting. Several options exist to overcome this issue: next to the application of alternative software permitting manual identification of targets and subsequent quantification, which can be prone to researcher bias and, therefore, is not presented here, imaging with a confocal microscope could facilitate quantification by reducing cross talk and background.

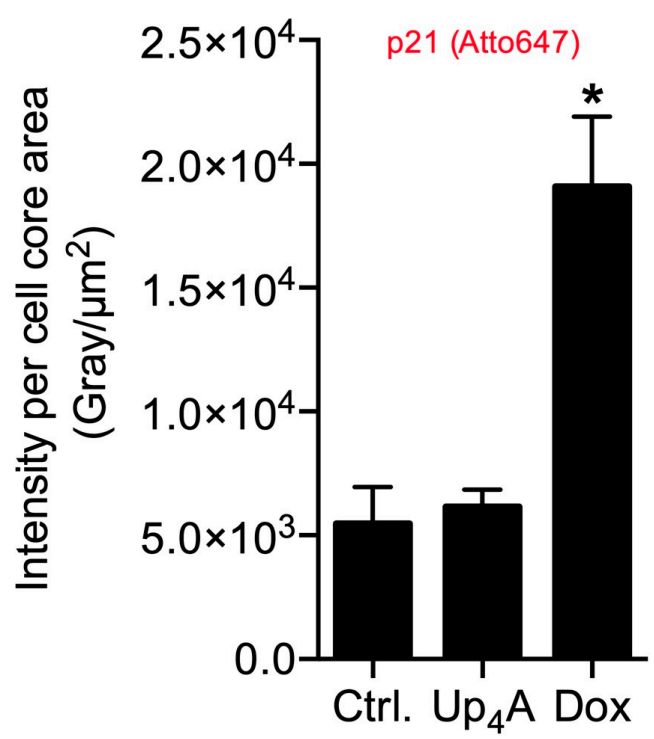

Figure 4. Quantification of p21 in primary rat smooth muscle cells upon stimulation with doxorubicin (Dox, $500 \mathrm{nmol} / \mathrm{L}$ ) and uridine-adenosine tetraphosphate $\left(\mathrm{Up}_{4} \mathrm{~A}, 100 \mu \mathrm{mol} / \mathrm{L}\right)$ for $48 \mathrm{~h}$. For analysis, intensity pixel sum per channel was normalized to cell core area. Bar graph represents mean $\pm \mathrm{SEM}$ of three independent experiments. Ctrl.: control.

Stimulation with different inducers as Dox and $\mathrm{Up}_{4} \mathrm{~A}$ varies in the markers analyzed for calcification and senescence. This underlines that, often, the detection of more than one senescence and calcification marker seems to be necessary for reliable and comparable results. In addition, in our experimental setting, we observed a certain level of cell batch specific variances in the expression levels of markers that are comparable to alternative protocols, like Western Blot and polymerase chain reaction (PCR). However, representative images also illustrate differences in marker expression between individual cells, especially for the investigated calcification marker OPN. This information is critical in order to understand the mechanisms and pathways within one cell during the calcification process. This information is lost in protocols that jointly analyze cell bulks. The current protocol can allow for the analysis of co-localization analysis within one cell and differences between cells of the same cell batch.

\subsection{Limitations}

The experimental design that is presented here is established for an in vitro experiment. Nevertheless, a transfer from cells to tissue should be possible. The development of appropriate pre-treatment and imaging of tissue section will require further optimization steps. In the case of SA- $\beta-$-Gal staining in tissue, we recommend using freshly frozen tissue and process the material immediately, as storage even at $-80^{\circ} \mathrm{C}$ reduces enzyme activity. In a proof of concept experiment, we tested RNAscope ${ }^{\mathrm{TM}}$ staining in frozen and paraffin-embedded aortic sections (unpublished data). We found a similar background in both materials and better results in paraffin-embedded tissue, which we attribute to easier handling. Alternative targets might be of interest, according to the focus of research. Here, our protocol provides some opportunities for variation: alternative target genes can be analyzed with the RNA in situ hybridization technique. The utilized protocol allows up to three different target 
genes. We used one of the available channels for immune-histological staining to make use of the optimal capacity of our microscope. If equipped with alternative hardware, combination with another secondary antibody for immune histological staining is possible, thus enriching the opportunities for multiplexing.

We are aware that there is a variety of alternative protocols. Alternative research models, such as primary cells from mouse or human, cell lines, as well as tissue sections from clinical or laboratory origin, are suitable alternatives. Next to that, a huge variety of different methods for the detection and quantification of our selected targets are possible. Each comes with its advantages and disadvantages that are shortly summarized in Table S1. In comparison to 5-bromo-4-chloro-3-indolyl- $\beta$-D-galactopyranoside $(X-G a l / B C I G)$ staining, we found fluorescence staining of SA- $\beta-$ Gal to be more robust, faster, and easier to image.

\section{Materials and Methods}

Figure 5 summarizes the complete and stepwise workflow of the experimental procedures. Primary VSMC from rat thoracic aorta was selected for experiments. Further special ordering information for kits with its components and antibodies can be found in the Supplementary Material (Tables S2 and S3).

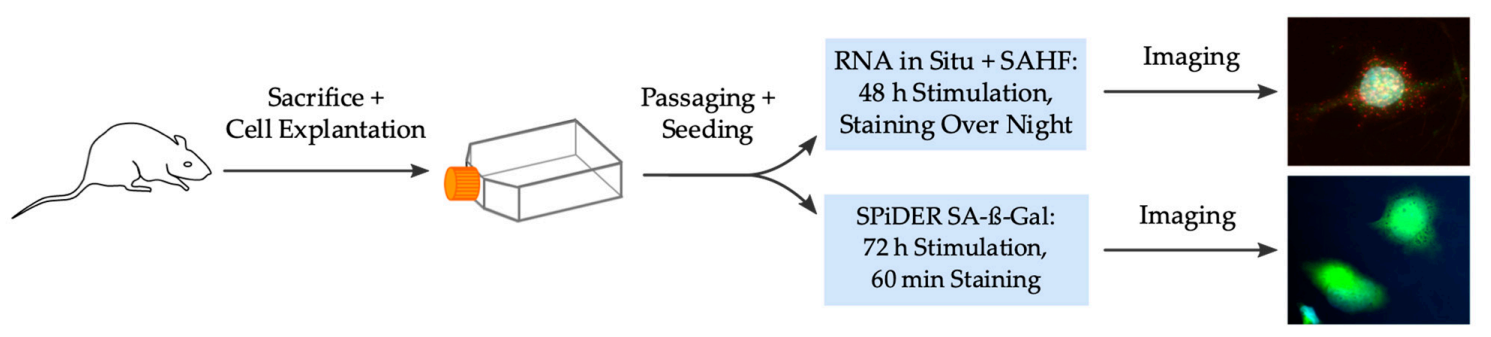

Figure 5. Scheme of the complete experimental workflow. SAHF: senescence-associated heterochromatin foci, SA-ß-Gal: senescence-associated ß-galactosidase.

\subsection{Cell Isolation and Culturing}

The study was in accordance with the EU Directive 2010/63/EU for animal experiments and it was approved by the Landesamt für Gesundheit und Soziales Berlin, Germany (T0211/02) and the animal facility of the Charité-Universitätsmedizin Berlin, Germany. The aorta of Wistar rats was prepared after euthanasia with sodium pentobarbital ( $400 \mathrm{mg} / \mathrm{kg}$ body weight) per intraperitoneal injection. After removal of the adventitia of rat thoracic aorta, primary rat VSMC were isolated by explant outgrowth, as described previously [17]. VSMC were cultured in Dulbecco Modified Eagle Medium (DMEM, Biochrom AG) containing $1 \mathrm{~g} / \mathrm{L}$ glucose, supplemented with 10\% fetal calf serum (FCS, Biochrom AG), penicillin (100 U/mL, Biochrom AG), and streptomycin $(0.1 \mathrm{mg} / \mathrm{mL}$, Biochrom AG). The cells were cultured in a humidified incubator at $37^{\circ} \mathrm{C}$ with $5 \%$ carbon dioxide. Cells at passages 4 were used for experiments. The cells were seeded in IBIDI 8 Well $\mu$-Slides (ibidi GmbH) for SA-B-Gal staining and 8-well LabTec Chamber Slides (Thermo Scientific) for RNA in situ hybridization. Cells were cultured for $24 \mathrm{~h}$ to a confluence of $70-80 \%$. It is essential to ensure subconfluence of cells prior stimulation, because confluence itself was described as an inducer of SA- $\beta-G a l$ activity [18]. The cells were serum starved for $24 \mathrm{~h}$ prior stimulation in DMEM containing $4.5 \mathrm{~g} / \mathrm{L}$ glucose, supplemented with $1 \%$ glutamin and antibiotics (penicillin $100 \mathrm{U} / \mathrm{mL}$, streptomycin $0.1 \mathrm{mg} / \mathrm{mL}$ ). This medium was also used for stimulation. For SA- $\beta$-Gal staining, the cells were stimulated for $72 \mathrm{~h}$, whereas for mRNA and SAHF detection a stimulation time of $48 \mathrm{~h}$ was used.

\subsection{Experimental Setting for Detection of $S A-\beta$-Galactosidase}

Information regarding the kit components and ordering information are summarized in the Supplementary Material (Table S3). 


\subsubsection{Preparations}

- Heat incubator to $37^{\circ} \mathrm{C}$ (no humidity and carbon dioxide control).

- Warm $4 \%$ formalin and PBS to $37^{\circ} \mathrm{C}$.

- Prepare Mcllvaine buffer: Mix 7.4 mL $0.1 \mathrm{~mol} / \mathrm{L}$ citric acid solution and $12.6 \mathrm{~mL} 0.2 \mathrm{~mol} / \mathrm{L}$ sodium phosphate solution and set $\mathrm{pH}$ to 6.0.

- Solve $20 \mu \mathrm{g}$ SPiDER-SA- $\beta$-Gal (Gerbu Biotechnologie) in $35 \mu \mathrm{L}$ dimethylsulfoxide (DMSO). Store aliquots at $-20^{\circ} \mathrm{C}$.

- Dilute Mcllvaine buffer 1:5 in ultrapure water and warm dilution to $37^{\circ} \mathrm{C}$. Dilute SPiDER-SA-B-Gal 1:500 in Mcllvaine buffer in order to obtain the working solution. Protect working solution from light.

- Prepare Hoechst working solution by dissolving Hoechst 33342 (Thermo Fisher) in the appropriate amount of water to obtain a stock concentration of $10 \mathrm{mg} / \mathrm{mL}$. The stock concentration can be aliquoted and stored at $-20^{\circ} \mathrm{C}$. To obtain the working solution, dilute Hoechst 1:2000 in PBS. Protect working solution from light.

\subsubsection{Staining Procedure}

The step-by-step staining procedure according to the manufacturer's (Dojindo) recommendations is given below. Figure 6 summarizes the main steps with an incubation time less than $40 \mathrm{~min}$ for the whole procedure.

1. After stimulation, aspirate medium and wash cells once with PBS.

2. Add $300 \mu \mathrm{L}$ of $4 \%$ buffered formalin to each well and fix cells for $3 \mathrm{~min}$ at room temperature, ensure the exact fixation time.

3. Aspirate formalin and wash three times with warm PBS.

4. Add $300 \mu \mathrm{L}$ of working solution per well and incubate for $30 \mathrm{~min}$ in the incubator under light protection. Caution: Ensure the right fixation times and $\mathrm{pH}$ conditions-this is critical for the $\beta$-Gal staining.

5. Aspirate working solution and wash cells twice with PBS.

6. Counterstain with Hoechst working solution for 5 min under light protection.

7. Aspirate solution and wash once with PBS.

8. Add $300 \mu \mathrm{L}$ of PBS and image within $24 \mathrm{~h}$.

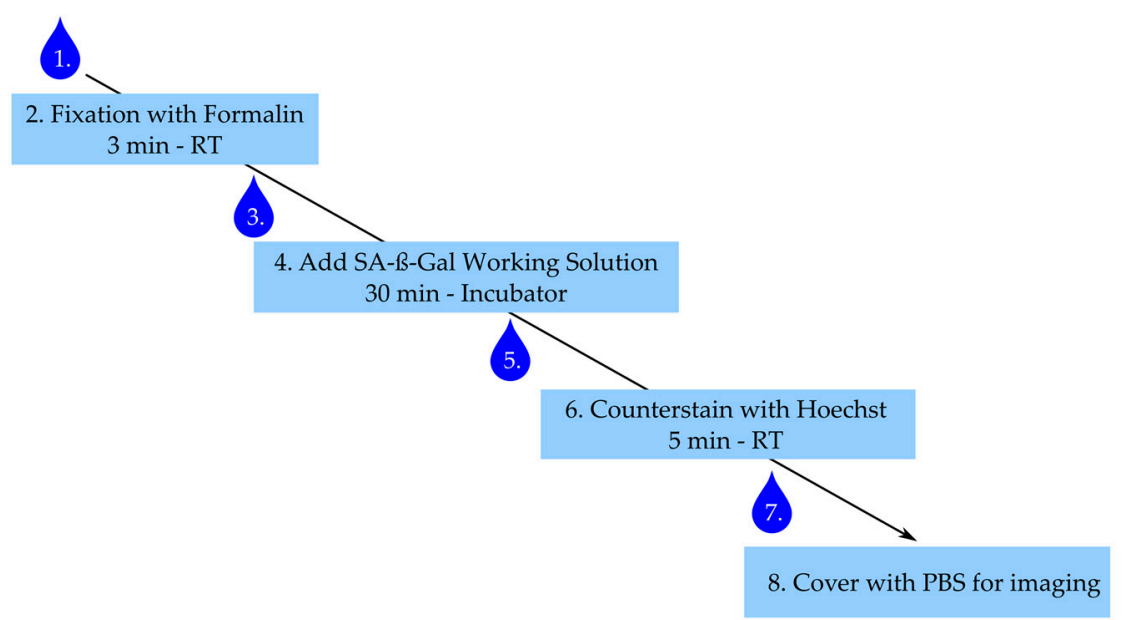

Figure 6. Staining procedure for senescence-associated- $\beta$-galactosidase (SA- $\beta-G a l)$. Numbering represents steps in staining procedure. Drop corresponds to wash step. RT: room temperature. 


\subsection{Experimental Setting for Detection of OPN, $p 21$ and SAHF}

All kit components for staining with the ordering information are summarized in the Supplementary Material (Table S3).

\subsubsection{Preparations}

- Add purified water to the humidity control tray and heat oven to $40^{\circ} \mathrm{C}$.

- Thaw ProLong ${ }^{\mathrm{TM}}$ diamond antifade medium (Thermo Scientific) at room temperature.

- Prepare wash buffer (ACD Bio) according to manufacturer's instructions.

- Heat mRNA probes (ACD Bio) gently at $40{ }^{\circ} \mathrm{C}$ for $10 \mathrm{~min}$ in a water bath, centrifuge probes and mix according to manufacturer's instructions.

- Dilute Protease III (ACD Bio) 1:15 with PBS.

- Prepare washing dishes for PBS and wash buffer.

- Prepare $10 \%$ Roti $^{\mathrm{TM}}$ ImmunoBlock (Carl Roth) by diluting in PBS.

- Prepare 1:500 dilution of primary antibody anti-histone H2A.X (phosphoS139) antibody [EP854(2)Y] (abcam) in 1\% Roti ${ }^{\mathrm{TM} I m m u n o B l o c k / P B S . ~}$

- Prepare 1:1,000 dilution of secondary goat anti-Rabbit IgG (H+L) highly cross-adsorbed antibody, Alexa Fluor 555 (Invitrogen) in 1\% Roti ${ }^{\mathrm{TM}}$ ImmunoBlock/PBS.

- If applicable: Prepare Hoechst stain, as explained above.

\subsubsection{Staining Procedure}

The step-by-step staining procedure according to the manufactures' recommendations (ACD Bio) is given below. Figure 7 summarizes the main points with several incubation steps, including one overnight incubation time.

1. After stimulation aspirate medium and wash cells once with PBS.

2. Add $300 \mu \mathrm{L}$ of $4 \%$ buffered formalin to each well and fix cells for $30 \mathrm{~min}$ at room temperature.

3. Aspirate formalin and wash twice with PBS.

4. Carefully detach the chamber from the slide according to the manufacturer's instruction and place the slide in a PBS filled washing dish. Caution: The glue is strong. Make sure to remove the glue of the chamber properly, otherwise the slide-coverslip combination becomes too thick.

5. Remove slide from the washing dish and thoroughly apply a barrier around each well with the ImmEdge ${ }^{\mathrm{TM}}$ hydrophobic barrier pen (ACD Bio) and place slide again in PBS.

6. Remove the slide from PBS, remove attaching PBS by gently inverting the slide and add $50 \mu \mathrm{L}$ of diluted Protease III to each well. Place slide in the humidity control tray, close humidity control tray, and incubate in the oven for $15 \mathrm{~min}$.

7. Remove slides from tray; remove protease from slide by inverting the slide and place slide in fresh PBS. Caution: The movement should be gently, but still removing the majority of liquid.

8. Remove slide from PBS, remove PBS by gently inverting the slide, and add $50 \mu \mathrm{L}$ of diluted target probes or one drop of positive or negative control to the according wells, place slides in the humidity control tray, and incubate in the oven for $120 \mathrm{~min}$.

9. Take slides out of the tray, inverse, and wash twice for $2 \mathrm{~min}$ each in wash buffer.

10. Remove attached liquid by gentle inversion and add one drop of amplifier 1-fluid (Amp 1-FL) to each well. Put slides in the humidity control tray in the oven for $30 \mathrm{~min}$.

11. Take slides out of the tray, inverse, and wash twice for 2 min each in wash buffer.

12. Remove attached liquid by gentle inversion and add 1 drop of Amp 2-FL to each well, place in the humidity control tray in the oven for $15 \mathrm{~min}$.

13. After $15 \mathrm{~min}$ take slides out of the tray, inverse and wash twice for 2 min each in wash buffer. 
14. Remove attached liquid by gentle inversion and add 1 drop of Amp 3-FL to each well, place in the humidity control tray in the oven for $30 \mathrm{~min}$.

15. Take slides out of the tray, inverse and wash twice for $2 \mathrm{~min}$ each in wash buffer.

16. Remove attached liquid by gentle inversion and add 1 drop of the selected Amp 4-FL to each well, place in the humidity control tray in the oven for $15 \mathrm{~min}$. Caution: For the multiplexing protocol we used Amp 4-FL A.

17. Take slides out of the tray, inverse and wash twice for 2 min each in wash buffer.

18. Add $100 \mu \mathrm{L}$ of $10 \%$ Roti $^{\mathrm{TM}}$ ImmunoBlock/PBS to each well and block for $1 \mathrm{~h}$ in the closed humidity control tray at room temperature.

19. Remove attached liquid by gentle inversion and wash once with PBS.

20. Add $50 \mu \mathrm{L}$ 1:500 dilution of primary anti-histone H2A.X (phosphoS139) antibody [EP854(2)Y] (Abcam) in 1\% Roti ${ }^{\mathrm{TM}}$ ImmunoBlock/PBS per well and incubate in the closed humidity control tray in the fridge overnight.

21. Remove attached liquid by gentle inversion and wash twice with PBS.

22. Add $50 \mu \mathrm{L}$ 1:1,000 dilution of secondary goat anti-rabbit IgG $(\mathrm{H}+\mathrm{L})$ Highly Cross-Adsorbed antibody, Alexa Fluor 555 (Invitrogen) in 1\% Roti ${ }^{\mathrm{TM}} \mathrm{Imm}$ monoBlock/PBS per well and incubate in the closed humidity control tray at room temperature for $60 \mathrm{~min}$.

23. Remove attached liquid by gentle inversion and wash twice with PBS.

24. Add 1 drop of 4',6-diamidino-2-phenylindole (DAPI) per well and incubate for $1 \mathrm{~min}$ at room temperature (alternatively add $50 \mu \mathrm{L}$ 1:2,000 Hoechst working solution and incubate for $5 \mathrm{~min}$ at room temperature).

25. Remove attached liquid by gentle inversion and wash once with PBS.

26. Add two drops of ProLong ${ }^{\mathrm{TM}}$ diamond antifade medium (Thermo Scientific) to each slide and gently apply the lid, make sure to gently remove all bubbles, and harden overnight in the fridge. Caution: The medium is highly viscose and can easily dry out. The cover slid is still moveable, even after drying. Be careful when cleaning the slide for imaging. Sealing the slide-lid combination with nail varnish can help in preventing the drying out and preserving the slides for later imaging.
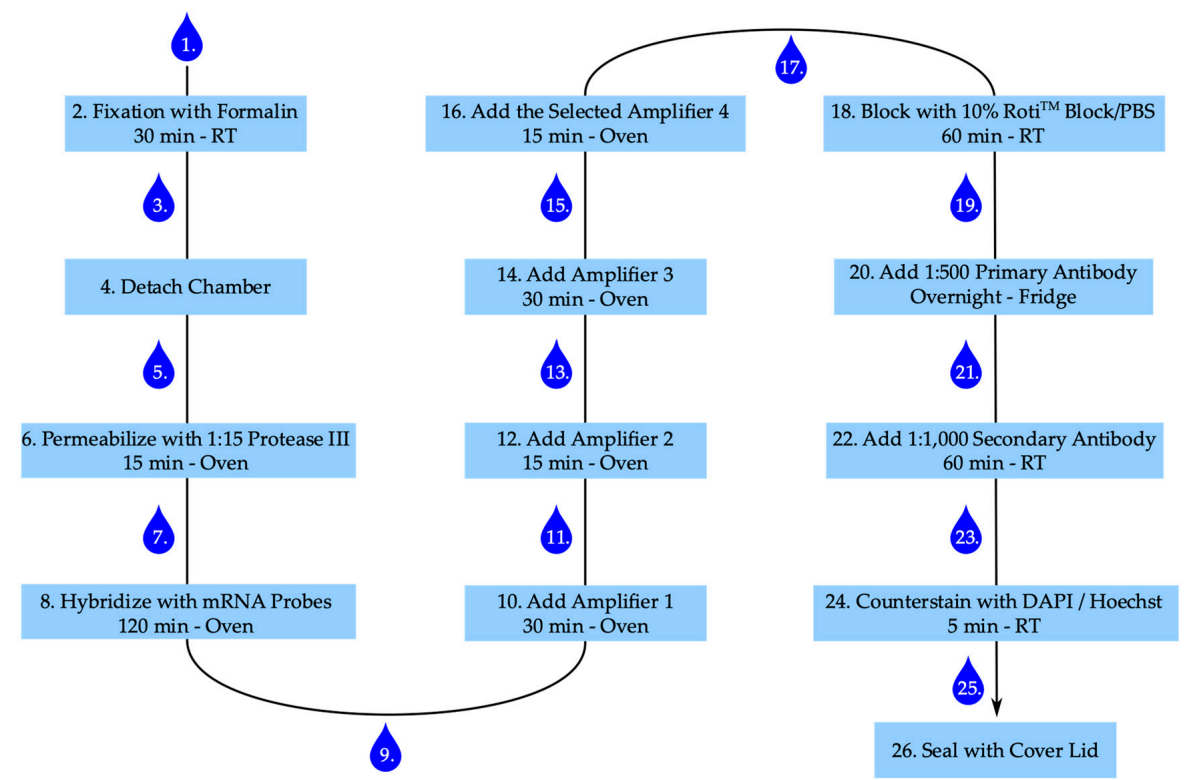

Figure 7. Staining procedure for RNAscope ${ }^{\mathrm{TM}}$ and senescence-associated heterochromatin foci. Numbering represents steps in staining procedure. Drop corresponds with washing step. RT: room temperature. 


\subsection{Imaging}

For imaging any fluorescence microscope with appropriate filter setting or a confocal microscope is possible. We obtained the images while using a Zeiss Axiovert $200 \mathrm{M}$ inverted transmitted light microscope using the filter sets, as illustrated in Table 1 . For image acquisition, the $40 \times$ F-Fluar objective with Immersol ${ }^{\mathrm{TM}}$ oil and the Zen software (Zeiss, Zen2 blue edition) was used. Each experiment was done in three independent experiments with duplicates for each stimulation drug. An acquisition of five images per well was done for analysis.

Table 1. Excitation/Emission Wavelength of the Dyes and Filters Used.

\begin{tabular}{|c|c|c|c|c|c|c|}
\hline Dye & $\begin{array}{l}\text { SPiDER } \\
\text { SA- } \beta-G a l\end{array}$ & $\begin{array}{c}\text { Hoechst } \\
33342\end{array}$ & Alexa 488 & Alexa 555 & Atto 647 & DAPI \\
\hline $\begin{array}{l}\text { Beam } \\
\text { Splitter }\end{array}$ & 532 & 395 & 495 & 570 & 660 & 395 \\
\hline $\begin{array}{c}\text { Filter Ex. } \\
\text { Wavelength }\end{array}$ & $500-530$ & $335-383$ & $450-490$ & $538-562$ & $625-665$ & $335-383$ \\
\hline $\begin{array}{c}\text { Filter Em. } \\
\text { Wavelength }\end{array}$ & 545-605 & $420-470$ & $500-550$ & $570-640$ & $665-715$ & $420-470$ \\
\hline $\begin{array}{c}\text { Ex. } \\
\text { Wavelength } \\
\text { of Dye }\end{array}$ & 528 & 348 & 493 & 553 & 644 & 348 \\
\hline $\begin{array}{c}\text { Em. } \\
\text { Wavelength } \\
\text { of Dye }\end{array}$ & 547 & 455 & 517 & 568 & 670 & 455 \\
\hline
\end{tabular}

\subsection{Quantification of Fluorescence Intensity}

The fluorescence intensity per channel was quantified while using the Zen2 software (Zeiss, blue edition). Five images per well/stimulation were analyzed for three independent experiments.

\subsection{Statistical Analysis}

Mean \pm SEM is given in the bar graph. Statistical significance between stimulation and respective control was analyzed using the Mann-Whitney-U Test. A $p$ value $<0.05$ was set as statistically significant.

\section{Conclusions}

In conclusion, the new experimental sets that are presented here allow for multiplexing and quantification of several markers of interest for calcification and senescence analysis in primary VSMC. This might not only help to reduce animal numbers for primary cell isolation and in vivo settings with regard to the 3R (Replacement, Reduction, and Refinement) thought of Russel and Burch [19], but also allow the visualization of markers of interest on a single cell basis.

Supplementary Materials: Supplementary materials can be found at http://www.mdpi.com/1422-0067/21/10/ 3475/s1.

Author Contributions: Conceptualization, M.S., J.H. and M.B.; methodology, J.H., M.S., M.B., and M.T.; experimental design and analysis, J.H., M.B. and M.S.; writing-original draft preparation, M.S., J.H. and M.B.; writing—review and editing, M.S., M.T., K.-U.E, and M.v.d.G.; visualization, J.H. and M.S.; project administration, M.S., K.-U.E. and M.v.d.G.; funding acquisition, M.S. and M.T. All authors have read and agreed to the published version of the manuscript.

Funding: The Sonnenfeld Stiftung (M.T., M.S.) the Berlin Institute of Health (M.S.) funded the research.

Acknowledgments: We thank Brigitte Egbers and Katharina Kuschfeldt for excellent technical assistance. We thank Manuel Herrmann-Fiechtner for support in figure creation. 
Conflicts of Interest: The authors declare no conflict of interest. The funders had no role in the design of the study; in the collection, analyses, or interpretation of data; in the writing of the manuscript, or in the decision to publish the results.

\section{Abbreviations}

$\begin{array}{ll}\text { Amp-FL } & \text { Amplifier fluid } \\ \text { Ctrl } & \text { Control } \\ \text { DAPI } & 4^{\prime} \text {,6-diamidino-2-phenylindole } \\ \text { DMSO } & \text { Dimethylsulfoxide } \\ \text { DNA } & \text { Deoxyribonucleic acid } \\ \text { DMEM } & \text { Dulbeccos-modified Eagle medium } \\ \text { Dox } & \text { Doxorubicin } \\ \text { FCS } & \text { Fetal calf serum } \\ \text { mRNA } & \text { Messenger Ribonucleic acid } \\ \text { OPN } & \text { Osteopontin } \\ \text { PCR } & \text { Polymerase chain reaction } \\ \text { PBS } & \text { Phosphate-buffered saline } \\ \text { RT } & \text { Room temperature } \\ \text { rVSMC } & \text { Rat vascular smooth muscle cell } \\ \text { SA- } \beta \text {-Gal } & \text { Senescence-associated } \beta \text {-galactosidase } \\ \text { SAHF } & \text { Senescence-associated heterochromatin foci } \\ \text { SEM } & \text { Standard error of mean } \\ \text { Up } 4 \text { A } & \text { Uridine adenosine tetraphosphate } \\ \text { VSMC } & \text { Vascular smooth muscle cell } \\ \text { X-Gal (BCIG) } & \text { 5-bromo-4-chloro-3-indolyl- } \beta \text {-D-galactopyranoside }\end{array}$

\section{References}

1. Jaminon, A.; Reesink, K.; Kroon, A.; Schurgers, L. The Role of Vascular Smooth Muscle Cells in Arterial Remodeling: Focus on Calcification-Related Processes. Int. J. Mol. Sci. 2019, 20, 5694. [CrossRef] [PubMed]

2. Nilsson, P.M.; Lurbe, E.; Laurent, S. The early life origins of vascular ageing and cardiovascular risk: The EVA syndrome. J. Hypertens 2008, 26, 1049-1057. [CrossRef] [PubMed]

3. Voelkl, J.; Lang, F.; Eckardt, K.-U.; Amann, K.; Kuro-O, M.; Pasch, A.; Pieske, B.; Alesutan, I. Signaling pathways involved in vascular smooth muscle cell calcification during hyperphosphatemia. Cell Mol. Life Sci. 2019, 76, 2077-2091. [CrossRef] [PubMed]

4. Henaut, L.; Mary, A.; Chillon, J.M.; Kamel, S.; Massy, Z.A. The Impact of Uremic Toxins on Vascular Smooth Muscle Cell Function. Toxins 2018, 10, 218. [CrossRef] [PubMed]

5. Tolle, M.; Reshetnik, A.; Schuchardt, M.; Hohne, M.; van der Giet, M. Arteriosclerosis and vascular calcification: Causes, clinical assessment and therapy. Eur. J. Clin. Investig. 2015, 45, 976-985. [CrossRef] [PubMed]

6. Sanchis, P.; Ho, C.Y.; Liu, Y.; Beltran, L.E.; Ahmad, S.; Jacob, A.P.; Furmanik, M.; Laycock, J.; Long, D.A.; Shroff, R.; et al. Arterial "inflammaging" drives vascular calcification in children on dialysis. Kidney Int. 2019, 95, 958-972. [CrossRef] [PubMed]

7. Herrmann, J.; Babic, M.; Tolle, M.; van der Giet, M.; Schuchardt, M. Research Models for Studying Vascular Calcification. Int. J. Mol. Sci. 2020, 21, 2204. [CrossRef] [PubMed]

8. Burton, D.G.; Matsubara, H.; Ikeda, K. Pathophysiology of vascular calcification: Pivotal role of cellular senescence in vascular smooth muscle cells. Exp. Gerontol. 2010, 45, 819-824. [CrossRef] [PubMed]

9. Muteliefu, G.; Shimizu, H.; Enomoto, A.; Nishijima, F.; Takahashi, M.; Niwa, T. Indoxyl sulfate promotes vascular smooth muscle cell senescence with upregulation of p53, p21, and prelamin A through oxidative stress. Am. J. Physiol. Cell Physiol. 2012, 303, C126-C134. [CrossRef] [PubMed]

10. Tuttle, C.S.L.; Waaijer, M.E.C.; Slee-Valentijn, M.S.; Stijnen, T.; Westendorp, R.; Maier, A.B. Cellular senescence and chronological age in various human tissues: A systematic review and meta-analysis. Aging. Cell 2020, 19, e13083. [CrossRef] [PubMed]

11. Carnero, A. Markers of cellular senescence. Methods Mol. Biol. (Cliftonn. J.) 2013, 965, 63-81. 
12. Noren Hooten, N.; Evans, M.K. Techniques to Induce and Quantify Cellular Senescence. J. Vis. Exp. 2017, 123, 55533. [CrossRef] [PubMed]

13. Giachelli, C.M. Ectopic calcification: Gathering hard facts about soft tissue mineralization. Am. J. Pathol. 1999, 154, 671-675. [CrossRef]

14. Jensen, E. Technical review: In situ hybridization. Anat. Rec. (Hoboken) 2014, 297, 1349-1353. [CrossRef] [PubMed]

15. Wang, F.; Flanagan, J.; Su, N.; Wang, L.C.; Bui, S.; Nielson, A.; Wu, X.; Vo, H.T.; Ma, X.J.; Luo, Y. RNAscope: A novel in situ RNA analysis platform for formalin-fixed, paraffin-embedded tissues. J. Mol. Diagn. 2012, 14, 22-29. [CrossRef] [PubMed]

16. Cappetta, D.; De Angelis, A.; Sapio, L.; Prezioso, L.; Illiano, M.; Quaini, F.; Rossi, F.; Berrino, L.; Naviglio, S.; Urbanek, K. Oxidative Stress and Cellular Response to Doxorubicin: A Common Factor in the Complex Milieu of Anthracycline Cardiotoxicity. Oxid. Med. Cell Longev. 2017, 2017, 1521020. [CrossRef] [PubMed]

17. Schuchardt, M.; Tolle, M.; Prufer, J.; Prufer, N.; Huang, T.; Jankowski, V.; Jankowski, J.; Zidek, W.; van der Giet, M. Uridine adenosine tetraphosphate activation of the purinergic receptor P2Y enhances in vitro vascular calcification. Kidney Int. 2012, 81, 256-265. [CrossRef] [PubMed]

18. Yang, N.-C.; Hu, M.-L. The limitations and validities of senescence associated- $\beta$-galactosidase activity as an aging marker for human foreskin fibroblast Hs68 cells. Exp. Gerontol. 2005, 40, 813-819. [CrossRef] [PubMed]

19. Russell, W.M.S.; Burch, R.L. The Principles of Humane Experimental Technique; Methuen \& Co Ltd.: London, UK, 1959.

(C) 2020 by the authors. Licensee MDPI, Basel, Switzerland. This article is an open access article distributed under the terms and conditions of the Creative Commons Attribution (CC BY) license (http://creativecommons.org/licenses/by/4.0/). 